Jurnal Dinamika Sosial Ekonomi Vol.21 No.1, Juni 2020 : 15-25

ISSN 1411-593X (print); ISSN 2721-3137 (online)

\title{
ANALISIS PENGARUH BAURAN PEMASARAN 7P TERHADAP KEPUTUSAN PEMBELIAN KOPI LUWAK MATARAM
}

\author{
THE ANALYSIS OF THE EFFECT OF MARKETING MIX (7PS) \\ ON PURCHASE DECISION OF KOPI LUWAK MATARAM
}

\author{
Rossa Dea Rosita*, Budiarto, Teguh Kismantoroadji \\ Program Studi Agribisnis, Fakultas Pertanian, \\ Universitas Pembangunan Nasional "Veteran" Yogyakarta \\ Jl. Padjajaran (Lingkar Utara 104) Condongcatur, Yogyakarta, Indonesia
}

Diterima tanggal : 26 Februari 2020 ; Disetujui tanggal 12 Maret 2020

\begin{abstract}
This study aims at analyzing the influence of the variables (product, price, place, promotion, people, physical evidence, and process) on purchase decision of kopi luwak. This research applied quantitative method. The method used in conducting this research was a case study. The method applied to determine the sample was incidental sampling involving 50 respondents. The types and the data sources were primary and secondary data. The techniques of data collection used were interview, observation, and documentation. In testing the instruments, this research employed validity and reliability testing. The data analysis technique and the hypothesis testing used in this research was multiple linear regression analysis. The results of this study indicate that the 7Ps marketing mix (product, price, place, promotion, people, physical evidence, and process) affect the purchase decision, in which promotion shows the highest impact on purchase decision, whereas people shows the least impact on purchase decision. Each of the other variables (product, price, place, promotion, people, and process) positively influences the purchase decision of kopi luwak. Meanwhile, physical evidence individually shows no effect on purchase decisions. The formulation of the marketing strategy, therefore, is to maintain the promotion and quality of Kopi Luwak Mataram according to the price.
\end{abstract}

Keywords: Kopi Luwak, Bantul, Marketing mix (7Ps), purchase decision 


\begin{abstract}
ABSTRAK
Penelitian ini bertujuan untuk menganalisis pengaruh dari variabel produk, harga, tempat, promosi, orang, bukti fisik, dan proses terhadap keputusan pembelian kopi luwak. Penelitian ini menggunakan metode kuantitatif. Metode pelaksanaan penelitian menggunakan metode studi kasus. Metode penentuan sampel dilakukan secara sampling incidental berjumlah 50 responden. Jenis dan sumber data yang digunakan adalah data primer dan sekunder. Metode pengumpulan data yang digunakan yaitu wawancara, observasi, dan dokumentasi. Pengujian instrumen menggunakan uji validitas dan uji reliabilitas. Teknik analisis dan pengujian hipotesis yang digunakan adalah analisis regresi linier berganda. Hasil penelitian ini menunjukkan bahwa bauran pemasaran 7P (produk, harga, tempat, promosi, orang, bukti fisik, proses) secara bersama-sama berpengaruh terhadap keputusan pembelian, dengan pengaruh tertinggi didominasi oleh variabel promosi dan pengaruh terendah adalah variabel orang. Variabel produk, harga, tempat, promosi, orang, proses masing-masing berpengaruh positif terhadap keputusan pembelian kopi luwak. Sedangkan untuk variabel bukti fisik secara individu tidak berpengaruh terhadap keputusan pembelian kopi luwak. Rumusan strategi pemasaran yang didapatkan yaitu mempertahankan promosi dan kualitas Kopi Luwak Mataram sesuai dengan harganya.
\end{abstract}

Kata kunci: Bauran pemasaran, Keputusan Pembelian, Kopi Luwak, Bantul

\title{
PENDAHULUAN
}

Indonesia merupakan negara agraris yang sebagian besar penduduknya menggantungkan hidup pada sektor pertanian. Selain sebagai penyedia lapangan pekerjaan, sektor pertanian juga berperan sebagai penyumbang devisa negara serta sebagai penyedia kebutuhan pangan dalam negeri. Produk pertanian mempunyai peranan penting bagi masyarakat. Salah satunya adalah sebagai bahan baku dalam kegiatan industri, baik industri besar, industri menengah, industri kecil maupun industri rumah tangga (Widodo, 2003). Kopi merupakan salah satu hasil komoditi perkebunan yang memiliki nilai ekonomis yang cukup tinggi di antara tanaman perkebunan lainnya dan berperan penting sebagai sumber devisa negara. Kopi tidak hanya berperan penting sebagai sumber devisa melainkan juga merupakan sumber penghasilan bagi tidak kurang dari satu setengah juta jiwa petani kopi di Indonesia (Hermawan, 2015). 
Rosita et.al., Analisis Pengaruh Bauran Pemasaran 7P Terhadap Keputusan..

Kopi luwak dikenal sebagai salah satu jenis kopi termahal di dunia. Kopi ini memiliki cita rasa yang khas yang membedakannya dengan jenis kopi yang lain. Hingga sekarang kopi luwak tetap dikenal produk minuman khas warisan leluhur yang cita rasanya dikenal secara luas hingga ke dunia internasional (Suriana, 2013). Hal ini dibuktikan dengan harga kopi luwak dipasaran yang mencapai lebih dari Rp 1.000.000,-/kg. Sedangkan untuk harga kopi biasa lainnya dipasaran hanya sekitar kurang lebih Rp 100.000,-/kg. Dapat dilihat bahwa harga kopi luwak jauh lebih mahal berkali-kali lipat dibandingkan dengan harga kopi biasa lainnya. Proses yang lebih rumit, rasa dan aroma yang lebih dari kopi lainnya, memang harga semahal ini pantas untuk kopi luwak (Ulfa, 2018).

Kopi Luwak Mataram merupakan sebuah home industry yang bergerak dibidang pertanian. Saat awal merintis usaha, Kopi Luwak Mataram ini hanya sebuah warung kedai kopi kecil dengan menyewa tanah disamping rumah pemilik dengan hanya Bapak Edi dan Ibu Merry saja berdua yang menjadi pegawainya selama merintis diawal usahanya. Karena masih kurangnya pengetahuan masyarakat tentang adanya kopi luwak, Kopi Luwak Mataram ini terus melakukan promosi dan kerjasama dengan para biro perjalanan. Berbeda dengan tempat kopi lainnya, kedai milik Ibu Merry Anggraeni yang berlokasi di Jalan Pelemwulung no.15, Banguntapan, Bantul, Yogyakarta ini menawarkan nuansa berbeda dibandingkan tempat ngopi pada umumnya.

Setiap industri rumah tangga akan semakin berkembang apabila jumlah permintaan akan produk meningkat, salah satu cara untuk menyikapi hal tersebut adalah melakukan strategi pemasaran yang tepat dengan mempengaruhi keputusan pembelian konsumen untuk memaksimalkan penjualannya (Noor, 2016). Salah satu strategi untuk mempengaruhi keputusan pembelian adalah dengan menerapkan bauran pemasaran. Bauran pemasaran merupakan konsep alat pemasaran untuk dapat mengembangkan strategi dengan terkendali yang dipadukan oleh perusahaan untuk dapat menarik konsumen yang sudah menjadi sasaran pasar (Sutrisno, 2018). Bauran pemasaran pada hakikatnya merupakan serangkaian strategi pemasaran yang ditempuh dalam upaya untuk mencapai tujuan tertentu. Untuk menentukan strategi dan bauran pemasaran 
Jurnal Dinamika Sosial Ekonomi, 21 (1) : 15-25

terbaik perusahaan melibatkan analisis, perencanaan, implementasi dan kendali pemasaran (Jutisa, 2018). Bauran pemasaran terdiri dari 7P yaitu produk (product), harga (price), tempat (place), promosi (promotion), orang (people), sarana fisik (physical evidence), proses (process). Ditengah persaingan yang semakin ketat perusahaan harus semakin jeli menetapkan strategi untuk memasarkan produknya ke masyarakat.

Pelaku usaha harus mempunyai strategi pemasaran yang juga merupakan bauran pemasaran sehingga mampu mempengaruhi keputusan pembelian yang akan berdampak kepada volume penjualan dan menghadapi ketatnya persaingan produk sejenis. Tujuan dan strategi ditetapkan dengan cara memanfaatkan kekuatan internal dan mengatasi kelemahan (Hanif, 2019). Namun industri rumah tangga Kopi Luwak Mataram yang tidak begitu paham atau tidak begitu memperhatikan strategi pemasaran tersebut, tetapi sebenarnya mereka sudah melakukan beberapa strategi hanya saja belum keseluruhan diterapkan. Kopi luwak kurang familiar dimata masyarakat karena harganya yang terkenal mahal, sehingga perlu strategi yang tepat guna menunjang usaha. Penelitian ini bertujuan untuk menganalisis pengaruh bauran pemasaran terhadap keputusan pembelian kopi luwak.

\section{METODE PENELITIAN}

Metode dasar penelitian yang digunakan dalam penelitian ini adalah metode kuantitatif. Metode ini digunakan untuk menjelaskan atau memberikan gambaran tentang Kopi Luwak Mataram. Metode pelaksanaan penelitian yang digunakan adalah metode studi kasus. Sebagai kasus dalam penelitian ini adalah kekhasan dari kedai Kopi Luwak Mataram yang dimana konsumen tidak hanya langsung duduk dan minum seperti di kedai kopi lain saat datang, namun konsumen diperlihatkan terlebih dahulu contoh hewan luwaknya kemudian diberi pengetahuan tentang proses pembuatan kopi luwak. Pemilihan Sampel dilakukan secara sampling insidental. Sampling insidental menurut Sugiyono (2015) dalam Andriyanto (2019) adalah teknik penentuan sampel berdasarkan kebetulan, yaitu siapa saja yang secara kebetulan/insidental bertemu dengan peneliti dapat 
Rosita et.al., Analisis Pengaruh Bauran Pemasaran 7P Terhadap Keputusan..

digunakan sebagai sampel dengan syarat sudah membeli dan berumur diatas 17 tahun. Kriteria sampel yaitu yang berusia produktif dan dapat berbahasa Indonesia. Jumlah sampel yang akan digunakan dalam penelitian ini yaitu berjumlah 50 responden.

Jenis dan sumber data yang digunakan ada dua, yaitu data primer dan data sekunder. Data primer diperoleh dari hasil kuesioner yang diberikan kepada responden Kopi Luwak Mataram. Sedangkan data sekunder diperoleh dari studi pustaka dan wawancara dengan pemilik Kopi Luwak Mataram. Metode pengumpulan data yang digunakan dalam penelitian ini, yaitu wawancara, observasi, dan dokumentasi. Dalam penelitian ini uji validitas dilakukan dengan melakukan korelasi bivariate. Uji reliabilitas dilakukan dengan melihat nilai Cronbach Alpha. Pengujian ini menggunakan software SPSS 22 (Ghozali, 2011 dalam Andriyanto, 2019).

Untuk melihat seberapa jauh pengaruh bauran pemasaran yang terdiri dari produk, harga, tempat, promosi, orang, bukti fisik, proses terhadap keputusan pembelian di Kopi Luwak Mataram menggunakan analisis Regresi Linier Berganda. Instrumen penelitian yang digunakan di uji coba terlebih dahulu sebagai alat ukur untuk mengambil data penelitian agar mendapatkan instrumen yang baik dan sesuai. Maka dari itu instrumen yang di uji coba harus valid dan reliabel. Tahapan dalam pengujian hipotesis adalah dengan melakukan Uji Koefisien Determinasi. Koefisien determinan digunakan untuk melihat seberapa besar variabel-variabel independen secara bersama-sama mampu memberikan penjelasan mengenai variabel dependen dengan melihat nilai Adjusted $\mathrm{R}^{2}$. Kemudian melakukan Uji F dan Uji t. Dilakukan dengan membandingkan tingkat signifikasi yang ditetapkan untuk penelitian dengan probability value dari hasil penelitian.

\section{HASIL PENELITIAN DAN PEMBAHASAN}

Analisis regresi berganda merupakan studi mengenai ketergantungan variabel dependen dengan salah satu atau lebih variabel independen. Analisa dalam penelitian ini terdiri dari 7 variabel independent yaitu variabel produk 
Jurnal Dinamika Sosial Ekonomi, 21 (1) : 15-25

$\left(\mathrm{X}_{1}\right)$, harga $\left(\mathrm{X}_{2}\right)$, lokasi $\left(\mathrm{X}_{3}\right)$, promosi $\left(\mathrm{X}_{4}\right)$, orang $\left(\mathrm{X}_{5}\right)$, bukti fisik $\left(\mathrm{X}_{6}\right)$, proses

$\left(\mathrm{X}_{7}\right)$ serta terdiri dari 1 variabel dependent yaitu keputusan pembelian $(\mathrm{Y})$.

Tabel 1. Hasil Regresi Linier Berganda

\begin{tabular}{lccc}
\hline \multicolumn{1}{c}{ Variabel } & $\beta$ & Sig. & Keterangan \\
\hline Konstanta & -5.829 & 0,055 & - \\
Produk (X1) & 0,235 & 0,002 & Signifikan \\
Harga (X2) & 0,370 & 0,028 & Signifikan \\
Tempat (X3) & 0,218 & 0,006 & Signifikan \\
Promosi (X4) & 0,387 & 0,000 & Signifikan \\
Orang (X5) & 0,147 & 0,004 & Signifikan \\
Variabel & $\beta$ & Sig. & Keterangan \\
X6 & 0,166 & 0,051 & Tidak Signifikan \\
X7 & 0,238 & 0,000 & Signifikan \\
Adj R & 0,873 & - & - \\
F & - & 0,000 & Signifikan \\
\hline
\end{tabular}

Sumber: Data Primer Diolah (2019)

Berdasarkan tabel persamaan regresi linier berganda dalam penelitian ini adalah sebagai berikut :

$\mathrm{Y}=-5.829+0,235 \mathrm{X}_{1}+0,370 \mathrm{X}_{2}+0,218 \mathrm{X}_{3}+0,387 \mathrm{X}_{4}+0,147 \mathrm{X}_{5}+0,166 \mathrm{X}_{6}+0,238 \mathrm{X}_{7}+\mathrm{e}$

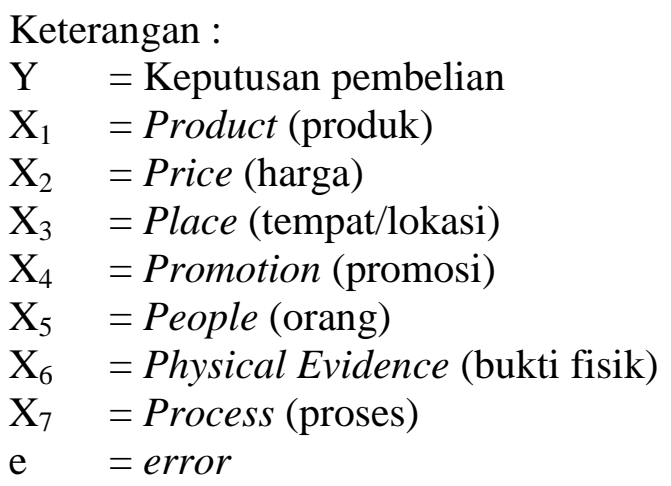

Dapat dilihat pada tabel 1 nilai adjusted $R$ Square adalah 0,873 artinya kemampuan variabel independen produk $\left(\mathrm{X}_{1}\right)$, harga $\left(\mathrm{X}_{2}\right)$, lokasi $\left(\mathrm{X}_{3}\right)$, promosi $\left(\mathrm{X}_{4}\right)$, orang $\left(\mathrm{X}_{5}\right)$, bukti fisik $\left(\mathrm{X}_{6}\right)$, dan proses $\left(\mathrm{X}_{7}\right)$ mampu menjelaskan variabel dependen keputusan pembelian sebesar $87,3 \%$ dan sisanya sebesar 12,7\% dijelaskan oleh variabel yang tidak dimasukkan dalam model. Uji F digunakan untuk mengetahui apakah variabel independen produk $\left(\mathrm{X}_{1}\right)$, harga $\left(\mathrm{X}_{2}\right)$, lokasi $\left(\mathrm{X}_{3}\right)$, promosi $\left(\mathrm{X}_{4}\right)$, orang $\left(\mathrm{X}_{5}\right)$, bukti fisik $\left(\mathrm{X}_{6}\right)$, dan proses $\left(\mathrm{X}_{7}\right)$ yang dimasukkan 
Rosita et.al., Analisis Pengaruh Bauran Pemasaran 7P Terhadap Keputusan..

dalam model regresi secara bersama-sama (simultan) berpengaruh terhadap variabel dependen keputusan pembelian (Y). Pada tabel 1 diketahui bahwa produk, harga, lokasi, promosi, orang, bukti fisik, dan proses secara bersama-sama berpengaruh terhadap keputusan pembelian kopi luwak pada Kopi Luwak Mataram (Sig. F $=0,000<\alpha=0,05)$.

Uji t digunakan untuk mengetahui apakah variabel independen produk $\left(\mathrm{X}_{1}\right)$, harga $\left(\mathrm{X}_{2}\right)$, lokasi $\left(\mathrm{X}_{3}\right)$, promosi $\left(\mathrm{X}_{4}\right)$, orang $\left(\mathrm{X}_{5}\right)$, bukti fisik $\left(\mathrm{X}_{6}\right)$, dan proses $\left(\mathrm{X}_{7}\right)$ yang dimasukkan dalam model regresi secara individu (parsial) berpengaruh terhadap variabel dependen keputusan pembelian (Y). Untuk pengujian secara parsial atau individu didapatkan hasil bahwa ada satu variabel bauran pemasaran yang kurang signifikan. Variabel tersebut adalah variabel bukti fisik dengan nilai signifikansi sebesar 0.051 yang artinya lebih besar dari nilai $\alpha(0.05)$. Hal ini dikarenakan konsumen tidak terlalu terpengaruh dengan variabel bukti fisik seperti dekorasi, fasilitas pendukung, dan keadaan bangunan selama masih dalam batas wajar, dan konsumen lebih terfokus dengan pengaruh dari variabel lainnya terutama produk kopi luwak itu sendiri.

Variabel produk berpengaruh terhadap variabel keputusan pembelian secara parsial (Sig. $\mathrm{t}=0,002<\alpha=0.05$ ). Dengan nilai koefisien 0,235 ke arah positif, yang berarti setiap kenaikan produk sebanyak satu satuan akan meningkatkan keputusan pembelian sebesar 0,235 . Produk menjadi variabel pokok dalam bauran pemasaran karena tujuan utama konsumen membeli adalah produk kopi luwak itu sendiri. Variabel harga berpengaruh terhadap variabel keputusan pembelian secara parsial (Sig. $\mathrm{t}=0.028<\alpha=0.05$ ). Dengan nilai koefisien 0,370 ke arah positif, yang berarti setiap kenaikan harga sebanyak satu satuan akan meningkatkan keputusan pembelian sebesar 0,370. Variabel harga berpengaruh terhadap keputusan pembelian karena ciri khas dari kopi luwak yang terkenal sebagai kopi termahal di dunia itulah yang membuat konsumen tertarik ingin mencoba dan membeli.

Variabel tempat berpengaruh terhadap variabel keputusan pembelian secara parsial (Sig. $t=0.006<\alpha=0.05$ ). Dengan nilai koefisien 0,218 ke arah positif, yang berarti setiap kenaikan tempat sebanyak satu satuan akan meningkatkan 
keputusan pembelian sebesar 0,218. Lokasi Kopi Luwak Mataram yang strategis dekat dengan objek wisata lainnya membuat wisatawan banyak berdatangan. Variabel promosi berpengaruh terhadap variabel keputusan pembelian secara parsial (Sig. $\mathrm{t}=0,000<\alpha=0,05$ ). Dengan nilai koefisien 0,387 ke arah positif, yang berarti setiap kenaikan tempat sebanyak satu satuan akan meningkatkan keputusan pembelian sebesar 0,387. Promosi yang dilakukan Kopi Luwak Mataram melalui brosur, media sosial, dan mengikuti bazar atau pameran membuat banyak konsumen tertarik.

Variabel orang berpengaruh terhadap variabel keputusan pembelian secara parsial (Sig. $\mathrm{t}=0,004<\alpha=0,05$ ). Dengan nilai koefisien 0,147 ke arah positif, yang berarti setiap kenaikan tempat sebanyak satu satuan akan meningkatkan keputusan pembelian sebesar 0,147. Pelayanan yang berbeda dari kedai kopi lainnya yang membuat Kopi Luwak Mataram ini menarik bagi konsumen karena berbeda dengan tempat lainnya. Variabel proses berpengaruh terhadap variabel keputusan pembelian secara parsial (Sig. $\mathrm{t}=0.000<\alpha=0.05$ ). Dengan nilai koefisien 0,238 ke arah positif, yang berarti setiap kenaikan tempat sebanyak satu satuan akan meningkatkan keputusan pembelian sebesar 0,238. Variabel proses cukup berpengaruh karena proses pemesanan, pengemasan, dan prosedur pembayaran yang sangat memudahkan konsumen, terutama bagi konsumen mancanegara.

Dengan melihat hasil analisis di setiap variabel dan indikator diperoleh beberapa usulan rumusan strategi pemasaran di Kopi Luwak Mataram, maka dari itu perlu disimpulkan lagi rumusan strategi pemasaran tersebut. Hasil analisis regresi linier berganda dan uji hipotesis menunjukkan bahwa pengaruh terbesar variabel bauran pemasaran terhadap keputusan pembelian adalah variabel promosi (Promotion) yaitu dengan nilai konstanta sebesar 0.387. Sedangkan untuk variabel bauran pemasaran yang pengaruhnya terendah terhadap keputusan pembelian adalah variabel orang (People) yaitu dengan nilai konstanta sebesar 0.147. Dan terdapat satu variabel bauran pemasaran yang tidak signifikan secara parsial atau individu yaitu variabel bukti fisik (Physical Evidence) dengan nilai signifikansi 0.051 dan nilai konstanta 0.166 . 
Rosita et.al., Analisis Pengaruh Bauran Pemasaran 7P Terhadap Keputusan..

Oleh karena itu variabel promosi sebaiknya menjadi perhatian utama untuk meningkatkan keputusan pembelian konsumen. Hal ini dikarenakan dengan promosi yang semakin baik akan semakin meningkatkan ketertarikan konsumen terhadap Kopi Luwak Mataram. Namun tetap harus memperhatikan variabel bauran pemasaran lainnya, mengingat variabel bauran pemasaran yang lainnya berpengaruh positif terhadap keputusan pembelian dan menjaga atau meningkatkan variabel bukti fisik yang kurang berpengaruh.

\section{KESIMPULAN}

\section{Kesimpulan}

Berdasarkan penelitian bauran pemasaran 7P yang sudah dilakukan maka dapat diambil kesimpulan yaitu secara bersama-sama (simultan) variabel bauran pemasaran 7P berpengaruh pada keputusan pembelian kopi luwak. Sedangkan secara individu atau masing-masing terdapat enam variabel bauran pemasaran yang signifikan atau berpengaruh pada keputusan pembelian kopi luwak. Variabel tersebut adalah variabel produk, harga, tempat, promosi, orang, dan proses. Sedangkan satu variabel tidak signifikan atau tidak berpengaruh pada keputusan pembelian yaitu variabel bukti fisik.

\section{Saran}

Berdasarkan hasil penelitian tersebut didapatkan saran bagi Kopi Luwak Mataram yaitu untuk mempertahankan kualitas kemasan Kopi Luwak Mataram yang sesuai dengan selera konsumen, yaitu dengan menggunakan kemasan produk lokal dari kerajinan tradisional untuk lebih membawa ciri khas Indonesia terutama untuk konsumen mancanegara. Menjaga kualitas kopi luwak tetap murni tanpa campuran kopi lain atau apapun lainnya sesuai dengan harganya atau memberikan tawaran dan potongan harga yang lebih menarik lagi bagi konsumen. Mempertahankan lokasi karena akses menuju Kopi Luwak Mataram sudah baik dan mudah ditemukan menggunakan GPS atau lebih banyak lagi bekerja sama dengan biro perjalanan untuk membawa wisatawan datang ke Kopi Luwak Mataram. 
Jurnal Dinamika Sosial Ekonomi, 21 (1) : 15-25

Mempertahankan promosi yang dilakukan menggunakan brosur saat pameran agar konsumen tetap tertarik untuk membeli atau lebih menginformasikan produk Kopi Luwak Mataram secara menarik lagi agar dapat lebih memotivasi konsumen untuk mau membeli produk kopi luwak. Mempertahankan pelayanan yang diberikan Kopi Luwak Mataram yaitu pelayanan yang simpatik, ramah, sopan santun, dan siap membantu pembeli. Mempertahankan desain tata ruang yang menarik atau memperluas bangunan di Kopi Luwak Mataram atau membuat meja dan kursi untuk konsumen dengan jumlah sedikit agar lebih menampung jumlah pembeli. Menambah dan meningkatkan lagi jumlah persediaan kopi luwak terutama untuk kemasan ukuran $50 \mathrm{gr}$.

\section{DAFTAR PUSTAKA}

Andriyanto, Lilik. (2019). Analisis Pengaruh Bauran Pemasaran (Marketing Mix 7-P) terhadap Keputusan Pembelian (Studi Kasus: Thiwul Ayu Mbok Sum Kecamatan Dlingo Kabupaten Bantul). Fakultas Pertanian. Universitas Pembangunan Nasional Veteran. Yogyakarta.

Andriyanto, L., Syamsiar, S., Widowati, I. (2019). Analisis Pengaruh Bauran Pemasaran (Marketing mix 7-P) terhadap Keputusan Pembelian di Thiwul Ayu Mbok Sum. Jurnal Dinamika Sosial Ekonomi. 20 (1) : 26-38.

A.S.S., Widodo, J., Zulianto, M. (2019). Strategi Bauran Pemasaran pada Pb. Dua Putradi Desa Ajung Kecamatan Kalisat Jember. Jurnal Pendidikan Ekonomi: Jurnal Ilmiah Ilmu Pendidikan, Ilmu Ekonomi, dan Ilmu Sosial. 13 (1) : 72-77. DOI: 10.19184/jpe.v13i1.10423.

Hermawan, Haris. (2015). Analisis Pengaruh Bauran Pemasaran Terhadap Keputusan, Kepuasan Dan Loyalitas Konsumen Dalam Pembelian Roti Ceria Di Jember. Jurnal Manajemen Dan Bisnis Indonesia. 1 (2) : 84-93.

Jutisa, D.D., Widodo, J., Wahyuni, S. (2018). Pengaruh Bauran Pemasaran terhadap Pengambilan Keputusan Menggunakan Jasa Bimbingan Belajar Primagama. Jurnal Pendidikan Ekonomi: Jurnal Ilmiah Ilmu Pendidikan, Ilmu Ekonomi, dan Ilmu Sosia. 12 (2) : 214-220. DOI: 10.19184/jpe.v12i2.8507.

Noor, Agus Mentari. (2016). Pengaruh Bauran Pemasaran 7(P) terhadap Keputusan Konsumen untuk Menggunakan Jasa Hotel Grand Sawit di Samarinda. eJournal administrasi bisnis. 4 (4) : 1031-1045.

Suriana, Neti. (2013). Pengertian dan Proses Kopi Luwak. https://www.puncakbukit.net/2013/07/kopi-luwak-pengertian-danproses.html. Diakses pada tanggal 25 Mei 2018. 
Rosita et.al., Analisis Pengaruh Bauran Pemasaran 7P Terhadap Keputusan..

Sutrisno, N.A.R.A., Widodo, J., Zulianto, M. (2018). Pengaruh Bauran Pemasaran terhadap Keputusan Pembelian Produk RM Ayam Bakar Wong Solo Jember. Jurnal Pendidikan Ekonomi: Jurnal Ilmiah Ilmu Pendidikan, Ilmu Ekonomi, dan Ilmu Sosial. 12 (2) : 259-263. DOI: 10.19184/jpe.v12i2.8568.

Ulfa, E.A., Ngesti, R., Djaja, S. (2018). Upaya Pemenuhan Kebutuhan Hidup Petani Kopi di Desa Harjomulyo Kecamatan Silo Kabupaten Jember. Jurnal Pendidikan Ekonomi: Jurnal Ilmiah Ilmu Pendidikan, Ilmu Ekonomi, dan Ilmu Sosial. 12 (1) : 116-121. DOI: 10.19184/jpe.v12i1.7619.

Widodo. (2003). Bioteknologi Industri Susu. Depok : Lacticia Press. 